\title{
EL TESTIMONIO TEXTUAL DE LA POLÍGLOTA COMPLUTENSE PARA LA EDICIÓN DEL TEXTO LUCIÁNICO EN 3 y 4 REYES
}

JOSÉ RAMÓN BUSTO SAIZ

CSIC. Madrid

Mantiene A. Rahlfs que las variantes del texto griego de la Políglota Complutense en los libros de los Reyes respecto al manuscrito 108 de Holmes y Parsons, del que, según nos consta ', dispusieron los editores de Alcalá, se han de explicar por el interés de los editores en acomodar su texto griego al texto hebreo masorético, acomodación profunda hasta el punto de elaborar los filólogos complutenses una nueva recensión griega ${ }^{2}$.

A. Sáenz-Badillos en su tesis doctoral (1972), recientemente publicada, tras la colación de 1 Re $1,1-8$, critica las conclusiones de Rahlfs, intentando alejar toda sospecha de arbitrariedad sobre el proceder de los sabios de Alcalá y defendiendo la idea de que éstos realizaron una edición basándose en los manuscritos griegos de que dispusieron, aunque reconoce que «el texto hebreo o griego»-supongo que quiere decir latino- «ha podido servir como punto de comparación, incluso para juzgar sobre la calidad de una u otra lección, y para decidirse por una u otra lectura" 3 .

Por mi parte, he colacionado íntegramente el texto de la Políglota Complutense en los libros de Samuel y Reyes con vistas a la edición

1 Cf. M. Revilla, La Políglota de Alcalá, Madrid 1917, pág. 98.

2 A. RaHLFS, Septuaginta Studien, 3, Gotinga 1911, págs. 18-23. Dice que el Cardenal Cisneros "wollte die griechische Uebersetzung dem hebräischen Urtext und der lateinischen Vulgata, mit denen er sie in seiner Polyglotte zusammenstellte, änhlich machen" (pág. 18) y que "Auf diese Weise ist eine ganz neue Rezension geschaffen, welche $M$ [= texto masorético] noch genauer entspricht, als die hexaplarische, mit der sie sich naturgemäss manchmal berührt, da Ximenez ebenso, wie Origenes, nach $M$ korrigiert hat” (págs. 22-23).

${ }^{3}$ La filología biblica en los primeros helenistas de Alcala, Estella 1990, págs. 413415. 
crítica del texto antioqueno que, junto con el Prof. N. Fernández Marcos, para los libros de Samuel, publicamos en $19899^{4}$, y que para los libros de los Reyes estamos preparando. Los resultados de la colación en los libros de Samuel aparecen recogidos en la introducción de la edición (págs. LXXX-LXXXI). En la presente contribución expondré los resultados que arroja la colación del texto en los libros de los Reyes donde el texto antioqueno, en cuanto parte del común texto septuagintal, presenta mayores divergencias en la reordenación de los diversos episodios narrados, cotejado con el texto hebreo y la Vulgata.

Creo poder dejar establecidos para estos libros los siguientes puntos.

1. El texto de la Políglota Complutense en los libros de los Reyes ( $=3$ y $4 \mathrm{Re}$ ), como también en los libros de Samuel, sigue habitualmente el del manuscrito Vat. Gr. 330, 108 de la edición de Holmes y Parsons. Hacer esta afirmación no entraña ninguna novedad ni dificultad.

2. Sin embargo, aunque se mantiene el texto del ms. 108, éste ha sido corregido de acuerdo con el texto hebreo y, en consecuencia, también con la Vulgata, ampliamente, en un conjunto de variantes que más que "textuales" me gustaría llamar "redaccionales". Es sabido que los libros de los Reyes tienen organizado el material literario - sus episodios y noticias- de manera diversa en los diferentes tipos textuales: texto hebreo y Vulgata, por un lado, y texto griego, septuagintal y antioqueno, por otro. Pues bien, aunque el "tenor textual" del texto complutense es antioqueno, ya que la Complutense sigue al ms. 108, el "tenor redaccional", valga la expresión, es el del texto masorético y la Vulgata.

Como los ejemplos podrían multiplicarse, voy a dar sólo algunos botones de muestra. Puede compararse el texto de 1 Re 5,1-3 (texto antioqueno):

TH om. / V om. / C om.

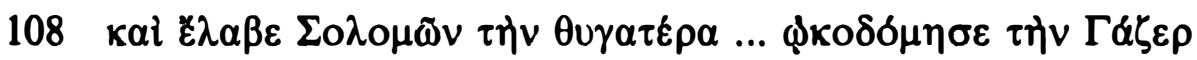

con el de 2,26-3,2 (texto ant.) $=2,46 \mathrm{a}-1$ (Br.-McL.) $=2,46-3,1(\mathrm{TH})=$ $3,1(\mathrm{~V})$

${ }^{4}$ N. Fernandez Marcos - J. R. Busto Saiz, El texto antioqueno de la Biblia Griega. I 1-2 Samuel, Madrid 1989. 
והממלכה נכונה ... ירושלם סביב TH

V confirmatum est igitur regnum ... Hierusalem per circuitum

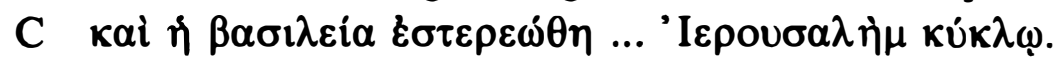

108 om.

En esa reorganización del texto son frecuentes las omisiones en la Complutense, de acuerdo con TH y V contra el ms. 108:

$1 \operatorname{Re} 2,1-14$ (texto ant.)

TH om. / V om. / C om.

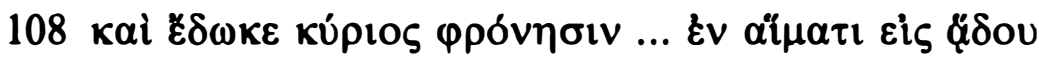

$1 \operatorname{Re} 2,26-37$ (texto ant.)

TH om. / V om. / C om.

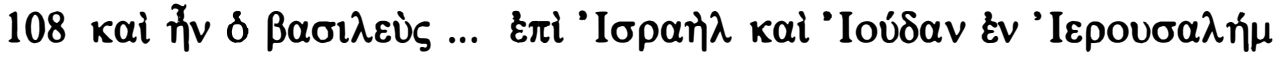

Hay también importantes añadidos de acuerdo con $\mathrm{TH}$ y $\mathrm{V}$, pero ausentes en 108:

$1 \operatorname{Re} 4,20-5,1(\mathrm{TH})=4,20-21(\mathrm{~V})$

יחודח וישראל רבים ... כל ימי חייו TH

V Iuda et Israhel innumerabiles ... cunctis diebus vitae eius

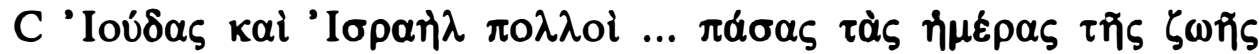
aủนỡ

108 om.

$1 \operatorname{Re} 5,5-8(\mathrm{TH})=4,25-28(\mathrm{~V})$

TH וישב יחודח וישראל לבטח .... איש כמשפטו

V habitabatque Iudas et Israhel ... iuxta constitutum sibi

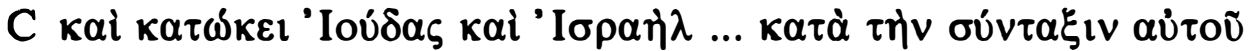

108 om.

Las dos variantes anteriores con el exacto tenor de la Complutense no se encuentran en ninguno de los manuscritos colacionados por Brooke - McLean, pero aparecen en A, x $(=247=$ Vat. Urbin. Gr. 1), representantes de la recensión hexaplar, la versión armenia y la versión Syh.

3. Resulta además que el mismo criterio es seguido en las frecuentes, y a veces amplias, omisiones que podemos hallar en la Complutense frente al ms. 108, y cuyo tenor puede ser considerado a veces "redaccional" y en otros casos meramente textual. Por ejemplo: 
$1 \operatorname{Re} 1,18$ (texto ant.)

TH om. / V om. / C om.

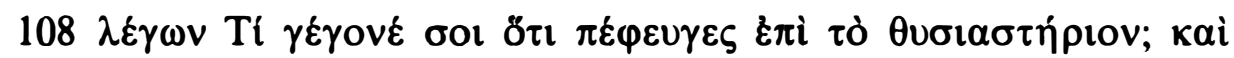
$\varepsilon \mathfrak{i} \pi \varepsilon v$

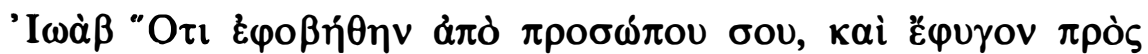

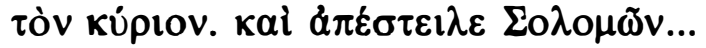

$1 \operatorname{Re} 3,25$ (texto ant.)

TH om. / V om. / C om.

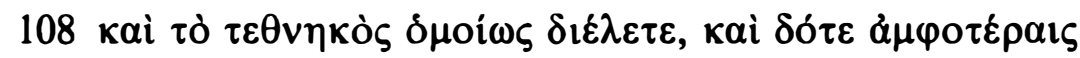

4. El mismo criterio se ha seguido en otras muchas variantes:

$1 \operatorname{Re} 5,4$ (texto ant.) = 5,15 (TH) = 5,1 (V)

אל שלמה כי שמע כי אתו משחו למלך TH

$\mathrm{V}$ ad Salomonem audivit enim quod ipsum unxissent regem

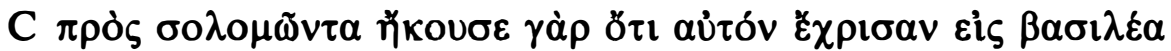

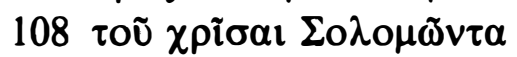

$1 \operatorname{Re} 6,11$ (texto ant.) =6,6 (TH) =6,6 (V)

חיצוע התחתנח חמש באמה רחבה TH

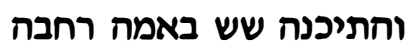

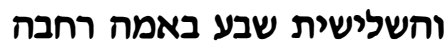

$\mathrm{V}$ tabulatum quod subter erat quinque cubitos habebat latitudinis et medium tabulatum sex cubitorum latitudinis et tertium tabulatum septem habens cubitos latitudinis

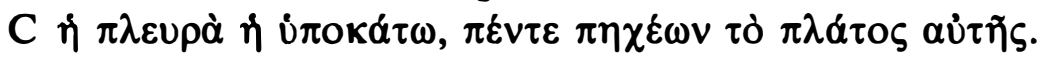

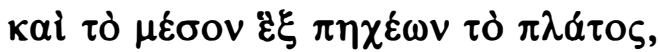

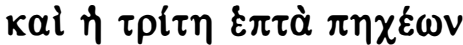

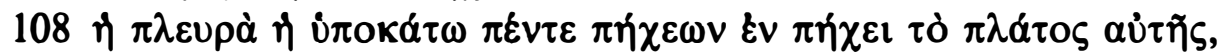

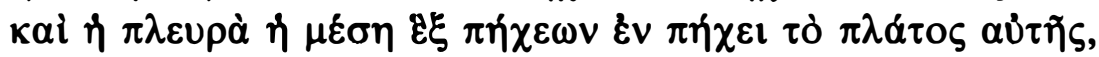

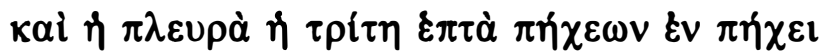

5. En consonancia con lo dicho, la grafia de los nombres propios va con el texto hebreo y la Vulgata, más con aquél que con ésta. Y no sólo la grafia, sino también la misma entidad del nombre.

$1 \mathrm{Re} 1,8$ (texto ant.) $=2,19$ (TH y V) et passim

TH אדניחו / V Adonia / C dowvíov / $108^{\circ}$ Opviá

$1 \operatorname{Re} 2,18$ (texto ant.) $=2,39$ (TH y V)

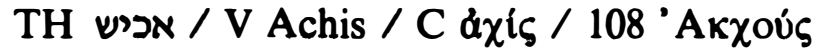

$1 \operatorname{Re} 4,3$ (texto ant., TH y V) 


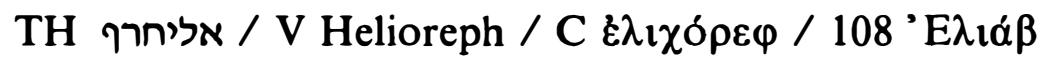

$1 \operatorname{Re} 4,3$ (texto ant., TH y V)

TH אחילוד / V Ahilud / C $\alpha \chi \chi \imath$ ¿

$1 \operatorname{Re} 4,5$ (texto ant., TH y V)

TH עזריהו / Azarias / C aלapias / 108 'Opvias

$1 \operatorname{Re} 4,5$ (texto ant., TH y V)

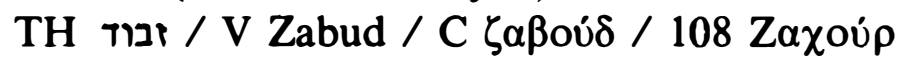

Así pues, respecto a los nombres propios me parece exacta la conclusión de A. Sáenz-Badillos, que mantiene que la grafía de los nombres propios está de acuerdo con la latina y, «algunas veces, más bien con la hebrea" y especialmente "con las formas adoptadas en el vocabulario del Tomo VI", lo que se explicaría, en su opinión, por los «fines prácticos y didácticos de la edición"s.

Por mi parte, añado la matización de que los editores complutenses acomodaron no sólo la grafía sino también la entidad de los nombres, como acabo de mostrar, con lo que conseguían eliminar las discrepancias existentes entre las diversas columnas, en algunos pasajes, acerca de la identidad de los protagonistas de los episodios narrados.

6. En algunos pocos casos donde el texto complutense se separa del ms. 108 y divergen el texto de la Vulgata y el hebreo, el texto de la Complutense va con el texto hebreo.

3 Re 3,15 (texto ant., TH y V)

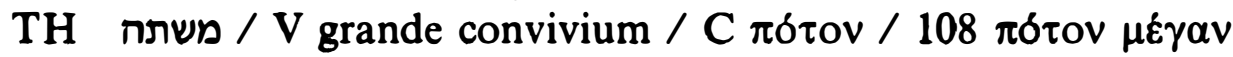

7. Los manuscritos y versiones más próximos son $\mathrm{A}, \mathrm{x}$, Arm $\mathrm{y}$ Syh., es decir, los representantes de la recensión hexaplar, como se puede comprobar especialmente en las grandes variantes de tipo redaccional más que textual, algunos de cuyos casos he citado más arriba, pero también en otras variantes menores. De forma que puede aceptarse la afirmación de Rahlfs según la cual los editores complutenses realizaron una nueva recensión.

s O. c., págs. 413-414. 


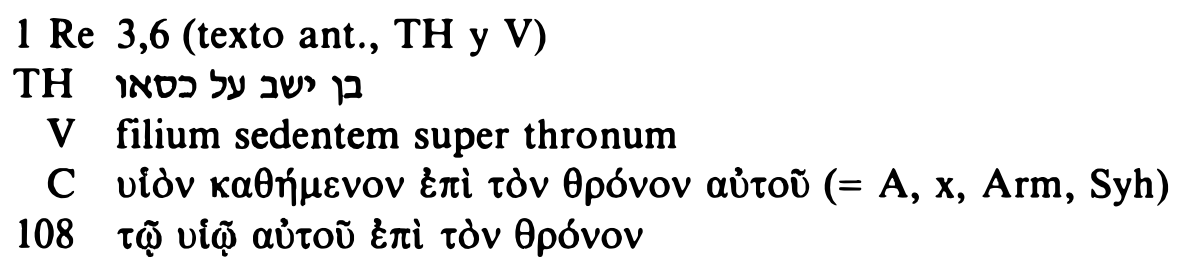

8. Aunque no es lo habitual, hay lecturas concretas de la Complutense que no se hallan en ningún manuscrito griego de los colacionados por Brooke - McLean ni por Holmes y Parsons. Dos ejemplos:

\section{$1 \operatorname{Re} 3,7$ (texto ant., TH y V)}

TH המלכת / V regnare fecisti / C $\varepsilon \beta \alpha \sigma i ́ \lambda \varepsilon v \sigma \alpha \varsigma / 108 \varepsilon \delta \omega \kappa \alpha \varsigma$

$1 \operatorname{Re} 1,8$ (texto ant.) $=2,19(\mathrm{TH} \mathrm{y} \mathrm{V})$

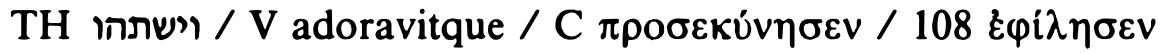

9. La cuestión que entonces se plantea es si los editores de Alcalá eligieron esas variantes tras hallarlas atestiguadas en manuscritos que tuvieron a su disposición o las retradujeron del latín -o del hebreo- como sugirieron J. Ziegler para Doce Profetas y L. Margolis para Josué 6 .

Sabemos que los editores dispusieron de varios manuscritos, hebreos, griegos y latinos, como escribe el Cardenal Cisneros en el prólogo a León X. Para los griegos, en concreto, repite Cisneros en el prólogo al lector que han tenido a su disposición "códices muy antiguos y de gran calidad" traídos de la Biblioteca Vaticana, a los que, según sus palabras, se añadieron otros muchos: «quibus etiam adiunximus non pauca" ?. La cuestión es, pues, si los editores selec-

\footnotetext{
${ }^{6}$ Cf. J. ZIEGLER, «Der griechische Dodekapropheton-Text der Complutenser Polyglotte», Biblica 25 (1944) 297-310, pág. 304. El trabajo que Margolis dejó inédito fue publicado por L. Greenspoon, "Max L. Margolis on the Complutensian Text of Joshuaw, Bulletin of the IOSCS 12 (1979) 43-56. Las conclusiones de Ziegler no satisficieron a J. W. WEVERS, "Septuaginta-Forschungen", Theologische Rundschau 22 (1954) 85-158, pág. 105, ni a N. FernánDEZ MARCos «El texto griego de la Complutense en Doce Profetas", Sefarad 39 (1979) 1-25, pág. 24. Véase también N. Fernández MARCos, "El texto griego", Anejo a la edición facsimile de la Biblia Políglota Complutense, Valencia 1987, págs. 36 ss.

${ }^{7}$ Entre ellos, hubo una copia de un manuscrito que había pertenecido al Cardenal Besarión. El ms. es con toda probabilidad el 68 de Holmes y Parsons (= Gr. 5 de la Bibl. Marc. de Venecia), mencionado en esta edición pero no colacionado. La copia, que debía encontrarse en la Biblioteca de la Universidad de Madrid, desapareció, al parecer incendiada durante el guerra civil española. Por lo cual, su colación me ha sido imposible.
} 
cionaron variantes de los manuscritos que tenían a su disposición o no tuvieron empacho en retraducir al griego a partir del latín o del hebreo. En la introducción a los libros de Samuel decíamos que frecuentemente algunos manuscritos griegos como $d=107, p=106$, $\mathrm{q}=120, \mathrm{t}=134$, apoyaban las lecturas complutenses divergentes del ms. 108, sin que pudiéramos señalar un manuscrito de los colacionados en Brooke - McLean que los filólogos de Alcalá hubieran seguido sistemáticamente. También allí aparecían variantes de poca entidad no atestiguadas en ningún manuscrito de los conocidos.

Es claro, como afirma Sáenz-Badillos, que «mientras no pueda esclarecerse definitivamente la cuestión de los mss. de los que disponían los editores, no podemos afirmar con plena seguridad que procedieran de modo arbitrario o al menos sin contar con sus manuscritos" 8 . En consecuencia, no podemos afirmar con seguridad absoluta que retradujeran y tampoco que no lo hicieran. Sobre todo, ante partidarios tan decididos de las retraducciones como Margolis o Ziegler. Margolis llega a afirmar que son retraducciones del latín al griego algunas lecturas existentes en manuscritos griegos, hecho éste que él atribuye al azar, aunque mejor podría haberlo atribuido al acierto de los complutenses 9. Ziegler, por su parte, sugiere que algunas lecturas de la Complutense son retraducciones del latín, aunque quizá no deban su autoría a los editores complutenses, sino que éstos las hubieran encontrado en manuscritos griegos influidos por la Vulgata.

En mi opinión, podemos, al menos, afirmar que los editores complutenses no se dejaron influir siempre por el texto hebreo y la Vulgata, ni los siguieron servilmente, lo que me parece inclina la balanza en el sentido contrario a las retraducciones. Las alteraciones que ralizaron sobre el ms. 108 habitualmente tienen más que ver con la crítica de fuentes que con la crítica textual, como creo haber mostrado. Desde luego, de haber pretendido los editores dar un texto griego acorde textualmente con el texto masorético su fracaso puede considerarse completo.

Por otro lado, se pueden aducir ejemplos que, aunque no lo demuestren apodícticamente, apoyan la idea de que los editores

${ }^{8}$ Cf. o. c., pág. 414

9 L. Greenspoon, o. c., pág. 45. 
complutenses no introdujeron correcciones que no hallaran atestiguadas por algún manuscrito griego. Veamos uno:

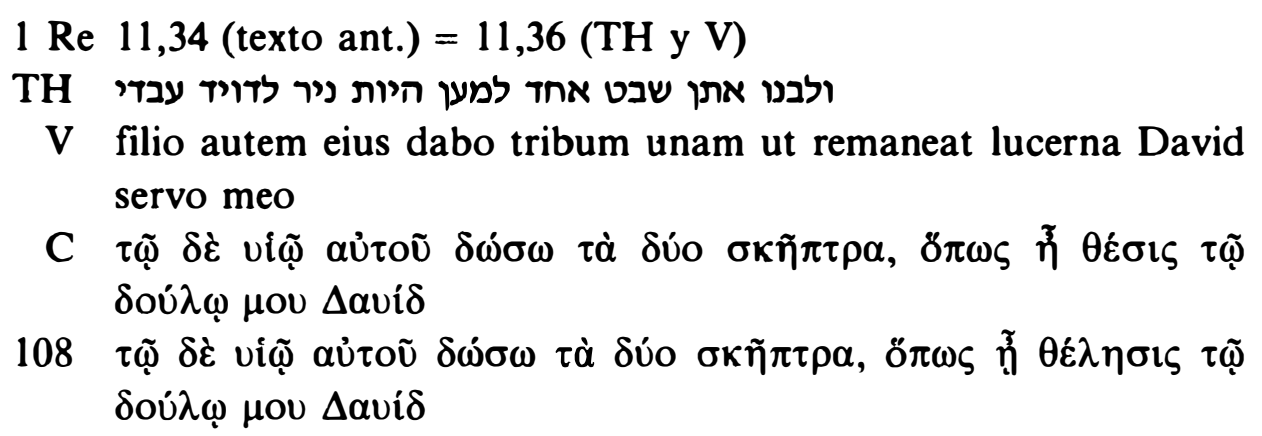

A partir de esta variante resulta evidente que los editores complutenses no se dejaron influir servilmente por el texto hebreo o la Vulgata. En caso contrario, ¿por qué no convirtieron las dos tribus del texto griego, en que coinciden todos los mss. griegos, en una sola de acuerdo con el hebreo y la Vulgata? Y al mismo tiempo,

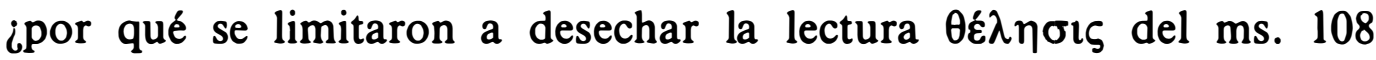
sustituyéndola por $\theta \varepsilon \dot{\varepsilon} \iota \varsigma$, presente en otros mss., en lugar de haber editado, - retraducido- un equivalente griego de ניר? Ningún manuscrito griego de los colacionados por Brooke - McLean ofrece un equivalente griego de ניר.

\section{CONCLUSIONES}

Mis conclusiones son, pues, las siguientes:

1. La Políglota Complutense ofrece habitualmente en 3-4 Re un texto "textualmente antioqueno", valga la expresión, porque sigue el mss. 108. Me parece, pues, que sigue vigente esta afirmación de Rahlfs ${ }^{10}$.

2. Pero constituye una nueva recensión porque desde un punto de vista literario el texto ha sido reordenado de acuerdo con el texto hebreo. En este punto me parece que la afirmación de Rahlfs también debe ser mantenida.

3. Con toda probabilidad les influyó en la elección de variantes

${ }^{10}$ Cf. o. c., pág. 18. En consecuencia, no me parece suficientemente matizada la afirmación en sentido contrario de A. SÁenZ Badillos, o. c., pág. 415. 
griegas el tenor del texto hebreo y corrigieron el texto del ms. 108 cuando les parecía de inferior calidad al de otros manuscritos griegos.

4. Sin embargo, no actuaron acomodando servilmente el texto griego al texto hebreo, ni de forma arbitraria con los manuscritos. En este punto, creo que las críticas de Sáenz-Badillos a Rahlfs están justificadas.

5. Evidentemente no podemos decir que nunca retradujeron del latín o del hebreo al griego, pero sí creo poder afirmar que si alguna vez lo hicieron hubo de ser muy rara y esporádicamente. Como creo haber mostrado más arriba, el texto hebreo sólo se impuso sobre el testimonio de los manuscritos griegos en los nombres propios.

6. El comportamiento del texto complutense en los libros de los Reyes es, pues, coherente con lo que ocurre en 1-2 Samuel, lo que quedó expuesto en la introducción a nuestra edición del texto antioqueno de esos libros.

7. Y finalmente, con vistas a nuestra edición, resulta que, también para los libros de los Reyes, como ya quedó dicho en Samuel, el texto de la Complutense no es útil como testimonio del texto antioqueno. Ello se debe a que el testimonio luciánico de la Complutense es el testimonio del ms. 108 simple y llanamente. Las variantes que encontramos en la Complutense sobre el ms. 108, precisamente por el modo de proceder de los editores de Alcalá, tal como lo he expuesto en este trabajo, no son testimonio del texto luciánico. 


\section{RESUMEN}

De la colación íntegra del texto griego de la Políglota Complutense en 3 y 4 Reyes para la edición crítica del texto antioqueno en esos libros, se deduce que dicho texto sigue habitualmente el del ms. Vat. Gr. 330 (=Verzeichnis 108). Constituye, sin embargo, una nueva recensión, porque el texto ha sido reordenado, desde un punto de vista literario, de acuerdo con el texto hebreo, como señaló Rahlfs. También se comprueba, contra Rahlfs, que los editores complutenses no actuaron de manera arbitraria. De ello se deduce que el testimonio de la Complutense no es útil para la edición del texto antioqueno, ya que su testimonio luciánico es sencillamente el del ms. 108.

\section{SUMMARY}

From the integral collation of the Greek text of 3 and 4 Kings in the Complutensian Polyglot Bible for the critical edition of the Antiochene text of those books, it may be deduced that the said text usually follows that of ms. Vat. Gr. 330 (= Verzeichnis 108). It, nevertheless, constitutes a new recension, because as Rahlfs noted, the text has been reorganized, from a literary point of wiew, in accordance with the Hebrew text. It is also evident, contrary to Rahlfs' opinion, that the editors of the Complutensian Polyglot did not act in an arbitrary manner. It follows therefrom that the testimony of the Complutensian Bible is not useful for the edition of the Antiochene text, since its Lucianic testimony is merely that of ms. 108. 